\title{
Increased Th1/Th17 Responses Contribute to Low-Grade Inflammation in Age-Related Macular Degeneration
}

\author{
Jiajia Chen ${ }^{\mathrm{a}}$ Wenzhan Wang ${ }^{\mathrm{a}}$ Qiuming $\mathrm{Li}^{\mathrm{b}}$ \\ aThe first department of ophthalmology, the First Affiliated Hospital of Zhengzhou University, \\ Zhengzhou, Henan, ${ }^{\mathrm{b} T}$ The second department of ophthalmology, the First Affiliated Hospital of \\ Zhengzhou University, Zhengzhou, Henan, China
}

\section{Key Words}

Age-related macular degeneration • Th1 • Th17

\begin{abstract}
Background/Aims: Age-related macular degeneration (AMD) is the primary cause of senior blindness in developed countries. Mechanisms underlying initiation and development of AMD remained known. Methods: We examined the $\mathrm{CD}^{+} \mathrm{T}$ cell compartments and their functions in AMD patients. Results: AMD patients presented significantly higher frequencies of interferon (IFN)- $\gamma$-expressing and interleukin (IL)-17-expressing CD4 ${ }^{+} T$ cells than healthy controls. The levels of IFN $-\gamma$ and IL-17 expression by $\mathrm{CD}^{+}{ }^{+} \mathrm{T}$ cells were significantly higher in AMD patients. These IFN- $\gamma$-expressing Th1 cells and IL-17-expressing Th17 cells could be selectively enriched by surface $\mathrm{CCR}^{+}$and $\mathrm{CCR}^{+}{ }^{+} \mathrm{CR} 6^{+}$expression, respectively. Th1 and Th17 cells from AMD patients promoted the differentiation of monocytes toward M1 macrophages, which were previously associated with retinal damage. Th1 and Th17 cells also increased the level of MHC class I expression in human retinal pigment epithelial (RPE)-1 cells, while Th1 cells increased the frequency of MHC class II-expressing RPE-1 cells. These proinflammatory effects were partly, but not entirely, induced by the secretion of IFN- $\gamma$ and IL-17. Conclusions: This study demonstrated an enrichment of Th1 cells and Th17 cells in AMD patients. These Th1 and Th17 cells possessed proinflammatory roles in an IFN- $\gamma$ - and IL-17-dependent fashion, and could potentially serve as therapeutic targets.
\end{abstract}

\section{Introduction}

C 2017 The Author(s) Published by S. Karger AG, Basel

Age-related macular degeneration (AMD) is the progressive damage in the macular region of the retina, most commonly occurring in people older than 60 years of age. This disease accounts for $8.7 \%$ of all blindness worldwide [1]. With the rapid increase in senior population globally, the prevalence of AMD is expected to further increase to approximately 196 million by the year 2020 and 288 million by the year 2040 [2]. Although anti-angiogenesis therapies have been effective in managing the wet form of AMD, with possibility to restore 
vision, these treatments tend to be expensive and are not widely available to most patients $[3,4]$. For the development of better treatments, more research on the underlying causes and the progressive mechanism of AMD is urgently needed

The etiology of AMD is unclear. It is currently thought that multiple mechanisms, such as age, environmental risk factors, and genetic predisposition, contribute to AMD pathogenesis, but the exact pathways are poorly understood [5]. Accumulating evidence now supports the idea that inflammatory pathways play a crucial intermediary role in the development and progression of AMD [6]. Many cells of the innate and adaptive immune system, including mast cells, macrophages, and lymphocytes, have been found in macular lesions and the adjacent choroid area $[7,8]$. Furthermore, genetic polymorphisms in many immune-related genes have been associated with altered AMD risk [9]. Together, these results suggest that dysregulation in the immune system may contribute to AMD progression, but the mechanistic details remain to be established. Indeed, chronic low-grade inflammation is being discovered in obesity, type 2 diabetes, osteoarthritis, and atherosclerosis and contributes to the initiation and exacerbation of these conditions [10-12].

Th1 and Th17 cells are characterized by the expression of signature cytokines interferon (IFN)- $\gamma$ and interleukin (IL)-17, respectively. Their roles in AMD have not been elucidated. Many autoimmune diseases and chronic low-grade inflammatory conditions present enrichment in Th1 and/or Th17 responses [13]. Th1-mediated IFN- $\gamma$ and tumor necrosis factor (TNF) production are known to promote M1 macrophage differentiation and increase the expression of MHC molecules [14], allowing increased antigen-presentation to $\mathrm{CD}^{+}$and $\mathrm{CD}^{+} \mathrm{T}$ cells and increased proinflammatory cytokine expression. Th17 cells also secrete TNF in addition to IL-17 and are implicated in multiple inflammatory mechanisms [15]. Interestingly, AMD patients presented increased serum levels of proinflammatory cytokines, including IL-1 $\beta$, TNF, and IL-17 [16]. Therefore, in this study, we examined the Th1 and Th17 cells in AMD patients.

\section{Materials and Methods}

\section{Study participants}

The study was performed in the First Affiliated Hospital of Zhengzhou University, with ethical approval from the ethics board of the First Affiliated Hospital of Zhengzhou University, and in accordance with the tenets of the Declaration of Helsinki. One hundred to $300 \mathrm{~mL}$ of peripheral blood samples were taken from 12 patients with wet form of AMD ( 6 males and 6 females) and 10 healthy control individuals (5 males and 5 females). Inclusion criteria included informed consent, age between 60 to 80 years, and complete access to medical records. Exclusion criteria included the presence of other ocular diseases, such as glaucoma, chronic uveitis, and ocular tumors, and the presence of other inflammatory diseases, such as diabetes, obesity, pathogenic infections, neoplastic malignancies, and inflammatory bowel diseases. No surgery or other forms of treatment were performed on the study participants at the time of sample collection.

\section{Sample processing and cell culture}

Peripheral blood mononuclear cells (PBMCs) were harvested from blood samples by Ficoll-Hypaque centrifugation method. For T cell stimulation, $3 \mu \mathrm{g} / \mathrm{mL}$ each of anti-human CD3 (OKT3) and anti-human CD28 (CD28.2, both from BioLegend) in PBS were added to a 96-well flat-bottom plate at $100 \mu \mathrm{L} /$ well overnight. The plate was then washed to remove excess antibodies before use. To detect IFN- $\gamma$ and IL-17 expression in T cells, PBMCs were added to the anti-CD3/CD28-coated plates at $2 \times 10^{5}$ cells/well for 5 h. For T cell coculture with monocytes, the T cells and the monocytes were added to the anti-CD3/CD28coated plates at $1 \times 10^{5}$ cells/well each. For T cell coculture with retinal pigment epithelial (RPE)-1 cell, a 96-well transwell plate (Corning) was used. A total of $4 \times 10^{4} \mathrm{RPE}-1$ cells/well were placed at the bottom chamber, and $2 \times 10^{5} \mathrm{Th} 1$, Th17, or Th1/Th17-depleted CD4+ ${ }^{+}$cells were added at the top chamber. The two chambers were separated by a porous membrane with $3-\mu \mathrm{m}$ pores. $2 \mu \mathrm{g} / \mathrm{mL}$ of anti-human CD3 and $2 \mu \mathrm{g} /$ $\mathrm{mL}$ of CD28 were added to the top chamber. After $72 \mathrm{~h}$, the RPE-1 cells were harvested for flow cytometry analysis.

\section{KARGER}




\section{Cellular Physiology Cell Physiol Biochem 2017;44:357-367 \begin{tabular}{l|l|l} 
and Biochemistry Published & DOI: 10.1159/000484907 & $\begin{array}{l}\text { C } 2017 \text { The Author(s). Published by S. Karger AG, Basel } \\
\text { www.karger.com/cpb }\end{array}$
\end{tabular}}

Chen et al.: Th1/Th17 Imbalance in AMD

\section{Cell sorting}

Monocytes were sorted using the human monocyte isolation kit (Stemcell). For sorting Th1 and Th17 cells, the human CD4 ${ }^{+} \mathrm{T}$ cell isolation kit (Stemcell) was first applied. Purified CD4+ $\mathrm{T}$ cells were then stained with PE-conjugated anti-human CCR3 antibody (G025H7) for 30 min on ice, washed, and treated with PE positive selection kit (Stemcell) to select for CCR3 ${ }^{+} \mathrm{CD} 4^{+} \mathrm{T}$ cells. For sorting Th17 cells, the staining and sorting process was repeated for PE-anti-human CCR4 (L291H4) and PE-anti-human CCR6 (G034E3) individually. For Th1/Th17 depletion, unconjugated anti-human CCR3, CCR4 and CCR6 antibodies were added to the antibody cocktail in the $\mathrm{CD}^{+} \mathrm{T}$ cell isolation kit. All procedures were carried out according to instructions provided by the manufacturer. For IFN- $\gamma$ and IL-17 neutralization, the NIB42 and eBio64CAP17 (eBioscience) monoclonal antibodies at $10 \mu \mathrm{g} / \mathrm{mL}$ of each were added, respectively. All other antibodies were used at concentrations recommended by the manufacturer.

Flow cytometry

After incubation and/or sorting, cells were washed and placed in PBS $+2 \%$ FBS prior to staining. If intracellular staining was performed, $5 \mu \mathrm{g} / \mathrm{mL}$ brefelding A was added for $5 \mathrm{~h}$ before harvest. For surface antigens, cells were stained with Live/Dead Violet stain (Invitrogen), anti-human CD3, CD4, HLA-A/B/C, and/or HLA-DP/DR/DQ (BioLegend) for $30 \mathrm{~min}$ on ice and washed twice. For intracellular staining, surfacestained cells were treated with Foxp3/Transcription Factor Staining Buffer Set (eBioscience) and were stained with anti-human IFN- $\gamma$, IL-17, T-bet and/or ROR $\gamma$ t (eBioscience) for $30 \mathrm{~min}$ on ice, and washed twice. All antibodies were used at concentrations recommended by the manufacturer. Cells were then fixed in $2 \%$ formaldehyde and analyzed in FlowJo software.

\section{Quantitative PCR}

Total RNA was collected using the RNeasy Mini kit (Qiagen). cDNA was synthesized using the SuperScript VILO Reverse Transcriptase kit (Thermo Fisher). The cDNA was then pre-amplified using the Taqman PreAmp Master Mix Kit and amplified using the Taqman gene expression assay system (Thermo Fisher), with primers/probes for each gene provided by the manufacturer. Relative mRNA was calculated by the $2^{-\Delta C \mathrm{t}}$ method using GADPH as the calibrator.

\section{Statistical analyses}

All statistical analyses were performed using Prism software. Two tailed $\mathrm{P}<0.05$ was considered as statistically significant. Mann-Whitney test was used for comparisons between healthy individuals and AMD patients. For comparisons of one parameter between multiple groups, Kruskal-Wallis test followed by Dunn's multiple comparisons was used. For comparisons of two parameters of more than one group, twoway ANOVA followed by Tukey's test was used. For experiments performed using the same sample under two conditions, Wilcoxon test was used.

\section{Results}

IFN- $\gamma^{+}$Th1 cells and IL-17+ Th17 cells were upregulated in AMD patients

To examine the role of Th1 and Th17 inflammation in AMD, we first examined the frequencies of these cells in the circulating blood of healthy controls and AMD patients. Using intracellular staining, we identified Th1 cells as IFN- $\gamma$-expressing CD4 ${ }^{+} \mathrm{T}$ cells, and Th17 cells as IL-17-expressing CD4+ ${ }^{+}$T cells (Fig. 1A). Compared to healthy controls, AMD patients demonstrated significantly elevated frequencies of Th1 and Th17 cells (Fig. 1B and 1C). We also investigated the levels of IFN- $\gamma$ and IL-17 by measuring mRNA transcription and protein secretion. The mRNA transcription levels of IFNG and IL17A were significantly elevated in $\mathrm{CD}^{+} \mathrm{T}$ cells from AMD patients (Fig. 2A and 2B). In the supernatant, the concentration of IFN- $\gamma$ and IL-17 was significantly higher in cell cultures containing AMD PBMCs than in cell cultures containing control PBMCs (Fig. 2C and 2D). Together, these results demonstrated that AMD patients presented an enrichment of Th1 and Th17 cells in PBMCs. 
Fig. 1. The percentage of circulating Th1 and Th17 cells was significantly upregulated in AMD patients. PBMCs were stimulated with anti-human CD3/CD28 for $5 \mathrm{~h}$ in the presence of brefeldin $\mathrm{A}$. The frequencies of IFN- $\gamma^{+}$and IL-17+ ${ }^{+} \mathrm{T}$ cells were examined by intracellular staining. (A) The gating strategy of IFN $-\gamma^{+}$and IL-17 ${ }^{+}$ cells in $\mathrm{CD}^{+} \mathrm{T}$ cells, in one representative AMD individual. The IFN- $\gamma^{+}$and IL-17 ${ }^{+}$ gates were drawn according to negative gates set by isotype control antibodies. (B) The frequency of IFN- $\gamma^{+} \mathrm{CD}^{+} \mathrm{T}$ cells in healthy control (Ctrl) individuals and AMD individuals. Welch's t test. ${ }^{* *} \mathrm{P}<0.01$. (C) The frequency of IL- $17^{+} \mathrm{CD} 4^{+} \mathrm{T}$ cells in healthy control (Ctrl) individuals and AMD individuals. Welch's t test. ${ }^{*} \mathrm{P}<0.05$.
Fig. 2. PBMCs from AMD patients expressed significantly higher levels of IFN- $\gamma$ and IL-17. PBMCs were stimulated with anti-human $\mathrm{CD} 3 / \mathrm{CD} 28$ for $5 \mathrm{~h}$. The $\mathrm{CD}^{+} \mathrm{T}$ cells were isolated for the measurement of IFNG and IL17A mRNA expression while the supernatant was collected for IFN- $\gamma$ and IL-17 ELISA. (A) The expression of IFNG by $\mathrm{CD}^{+}$ $\mathrm{T}$ cells from Ctrl individuals and AMD patients. Welch's t test. ${ }^{* *} \mathrm{P}<0.01$. (B) The expression of IL17A by $\mathrm{CD} 4^{+} \mathrm{T}$ cells from Ctrl individuals and AMD patients. Welch's t test. ${ }^{*} \mathrm{P}<0.05$. (C) The IFN- $\gamma$ concentration in culture supernatant from Ctrl PBMCs and AMD PBMCs. Welch's t test. ${ }^{*} \mathrm{P}<0.05$. (D) The IL-17 concentration in culture supernatant from Ctrl PBMCs and AMD PBMCs. Welch's t test. ${ }^{* * *} \mathrm{P}<0.001$.
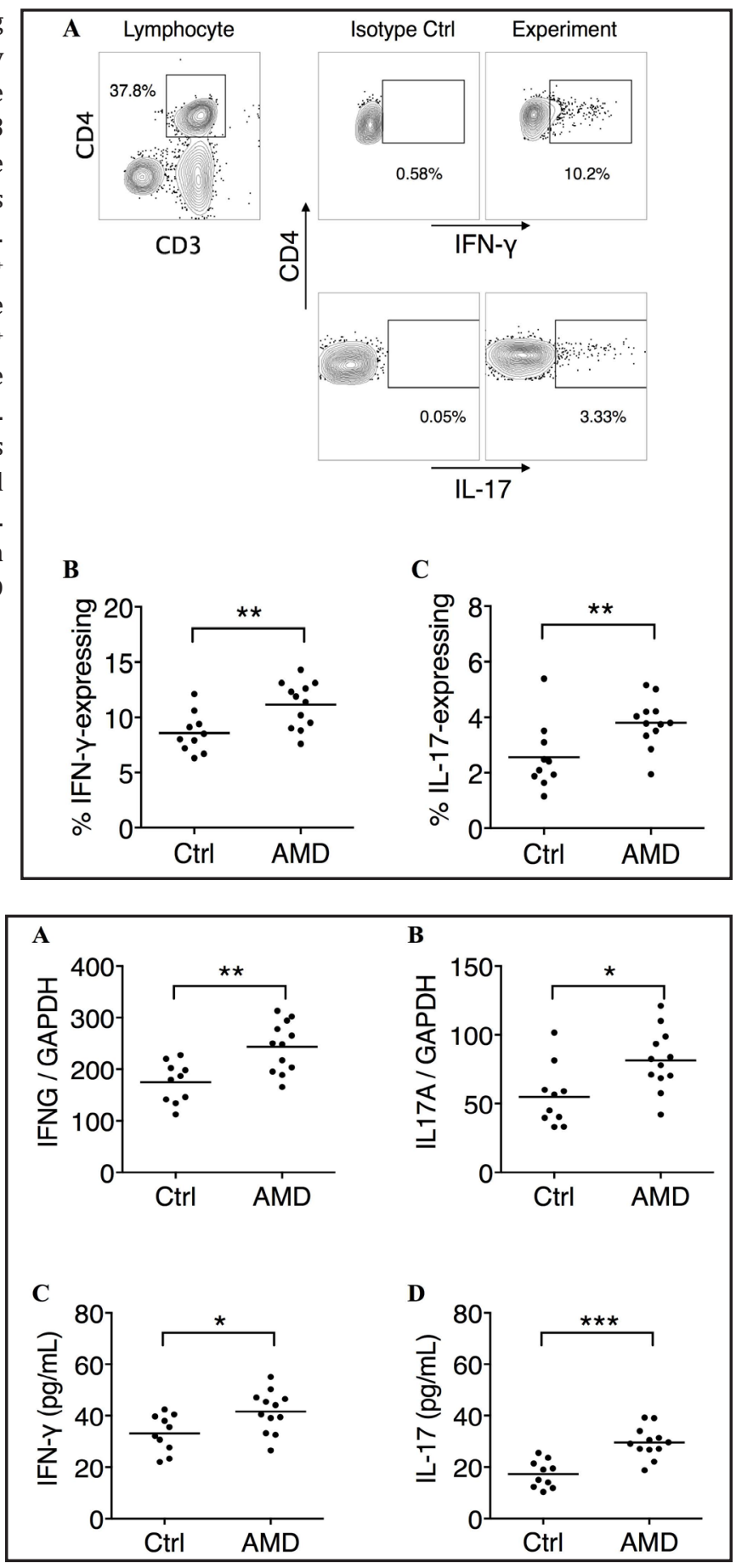

$\mathrm{CXCR}^{+}$and $\mathrm{CCR}^{+} \mathrm{CCR}^{+}$could be used as surface markers for Th1 and Th17 cells, respectively

To allow functional analyses of Th1 and Th17 cells, we examined surface marker sets that could be used to identify Th1 and Th17 cells. CXCR3 ${ }^{+}$and CCR $4^{+}$CCR6 ${ }^{+}$phenotypes were previously associated with Th1 and Th17 cells, respectively $[17,18]$. We found that CXCR3 ${ }^{+} \mathrm{CD}^{+}$ T cells expressed large amounts of IFN- $\gamma$ but very little IL-17 (Fig. 3A). Similarly, CCR4 ${ }^{+}$CCR6 ${ }^{+}$ $\mathrm{CD}^{+}{ }^{+} \mathrm{T}$ cells expressed high level of IL-17 but little IFN- $\gamma$. Also, CXCR3 ${ }^{+} \mathrm{CD}^{+}{ }^{+} \mathrm{T}$ cells expressed 
significantly higher level of Th1 transcription factor Tbet than $\mathrm{CCR}^{+} \mathrm{CCR}^{+} \mathrm{CD}^{+}{ }^{+} \mathrm{T}$ cells, while $\mathrm{CCR} 4^{+} \mathrm{CCR}^{+}{ }^{+} \mathrm{CD} 4^{+}$ $\mathrm{T}$ cells expressed significantly higher level of Th17 transcription factor ROR $\gamma$ t than $\mathrm{CXCR}^{+} \mathrm{CD}^{+}{ }^{+} \mathrm{T}$ cells (Fig. 3B). These data demonstrated that $\mathrm{CXCR}^{+}{ }^{+}$and CCR $4^{+} \mathrm{CCR}^{+}{ }^{+}$phenotypes could be used to sort Th1 and Th17 cell, respectively, for functional analyses.

Th1 and Th17 cells contributed to M1 macrophage differentiation of monocytes

Macrophages are commonly separated into two major types, namely the IL$12^{\text {high }}$ IL- $10^{\text {low }}$ M1 macrophage, which plays a critical role in antigen presentation and mediating immunity against infections, and the IL- $10^{\text {high }}$ IL$12^{\text {low }}$ M2 macrophage, which demonstrates higher phagocytosis and is thought to promote tissue remodeling [19]. Prior to the induction of retinal lesion, macrophages enriched in the M1 type were found to infiltrate the interphotoreceptor matrix in mice, while in CCR2-deficient mice

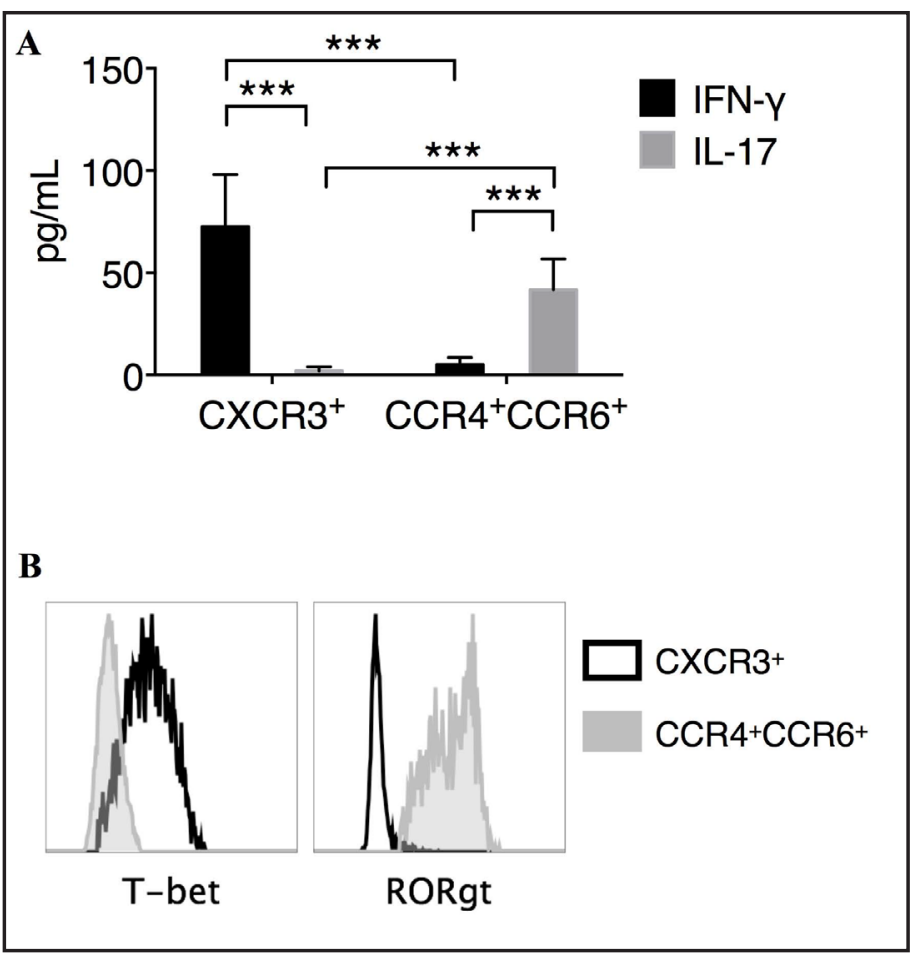

Fig. 3. Th1 and Th17 cells are enriched in the $\mathrm{CXCR}^{+}$and CCR $4^{+} \mathrm{CCR} 6^{+} \mathrm{CD}^{+} \mathrm{T}$ cell fractions, respectively. $\mathrm{CD} 4^{+} \mathrm{T}$ cells were negatively enriched from PBMCs by magnetic sorting, and CXCR3 ${ }^{+}$ and $\mathrm{CCR}^{+} \mathrm{CCR}^{+}{ }^{+}$cells were then positively selected by magnetic sorting. The sorted cells were then stimulated with anti-human CD3/CD28 antibodies for $5 \mathrm{~h}$. The supernatant was collected by ELISA measurement of cytokines, and the cells were harvested for T-bet and ROR $\gamma$ t nuclear staining. (A) The expression of IFN- $\gamma$ and IL- 17 by $\mathrm{CXCR}^{+}{ }^{+} \mathrm{CD} 4^{+} \mathrm{T}$ cells and CCR $4^{+} \mathrm{CCR} 6^{+} \mathrm{CD} 4^{+} \mathrm{T}$ cells. Two-way ANOVA followed by Tukey's test. ${ }^{* *} \mathrm{P}<0.001$. (B) Expression of T-bet and RORyt by $\mathrm{CXCR}^{+}{ }^{+} \mathrm{CD} 4^{+} \mathrm{T}$ cells (black) and CCR $4^{+} \mathrm{CCR} 6{ }^{+} \mathrm{CD}^{+}{ }^{+} \mathrm{T}$ cells (gray). with no infiltration of macrophages, no retinal lesion was observed [20]. Macrophages also stimulate the expression of complement factors and other inflammatory mediators by RPE cells through soluble macrophage-derived cytokines [21]. Given the association between macrophages and AMD, we examined the effect of Th1 and Th17 cells on macrophage differentiation. We co-incubated circulating monocytes from AMD patients with autologous CXCR3 ${ }^{+} \mathrm{CD}^{+}{ }^{+} \mathrm{T}$ (Th1) cells, $\mathrm{CCR}^{+}{ }^{+} \mathrm{CR} 66^{+} \mathrm{CD}^{+}{ }^{+} \mathrm{T}$ (Th17) cells, or CCR3- and CCR4/CCR6-depleted CD4 ${ }^{+} \mathrm{T}$ cells. The differentiation of macrophages was monitored. Macrophages incubated with Th1 and Th17 cells demonstrated significant higher expression of $I L 12 A$ and $I L 12 B$ (Fig. 4A), while the monocytes/macrophages incubated with Th1/Th17-depleted CD4 $4^{+} \mathrm{T}$ cells demonstrated significantly higher IL10. The level of IL-12 and IL-10 in culture supernatant presented the same trend. Together, these data demonstrated that Th1 and Th17 cells from AMD patients potently promoted the expression of M1, but not M2, cytokines for macrophages. We also performed these experiments using Th1 and Th17 cells and Th1/Th17-depleted CD4+ $\mathrm{T}$ cells from healthy control subjects, and observed that the macrophage $I L 12 A, I L 12 B$ and $I L-10$ expression, as well as the IL-12 and IL-10 secretion, in healthy control individuals followed a similar trend with that in AMD patients (Fig. 4B), demonstrating that the Th1 and Th17-mediated effects were not specific to AMD patients but also observable in healthy individuals. 
Fig. 4. Th1 and Th17 cells promoted M1 macrophage differentiation. Monocytes were negatively enriched from PBMCs by magnetic sorting, and were incubated with sorted $\mathrm{CXCR}^{+}{ }^{+} \mathrm{CD} 4^{+}$ (Th1, filled circle), $\mathrm{CCR} 4{ }^{+} \mathrm{CCR} 6{ }^{+} \mathrm{C} \mathrm{D} 4^{+}$ (Th17, open circle) cells, or Th1/Th17depleted (filled triangle) $\mathrm{CD}^{+} \mathrm{T}$ cells at 1:5 ratio, in the presence of anti-human CD3/ CD28 antibodies. After 0,3 , and 6 days of coculture, the monocyte/macrophages were harvested for mRNA examination. The supernatant was collected for ELISA. Mean \pm SD of data from all 12 AMD patients were presented. (A) The IL12A, IL12B,
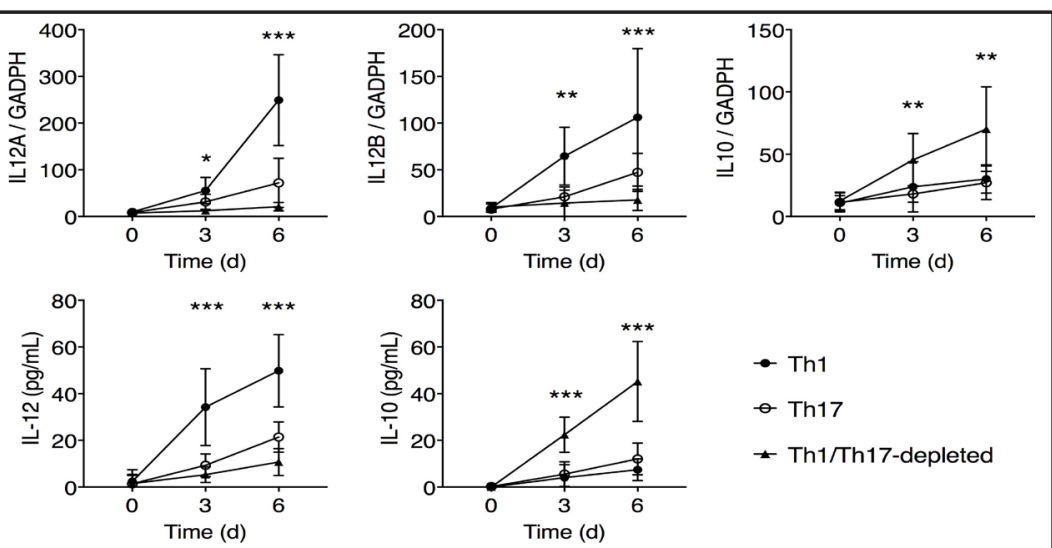

$\bullet$ Th1

- Th17

- Th1/Th17-depleted
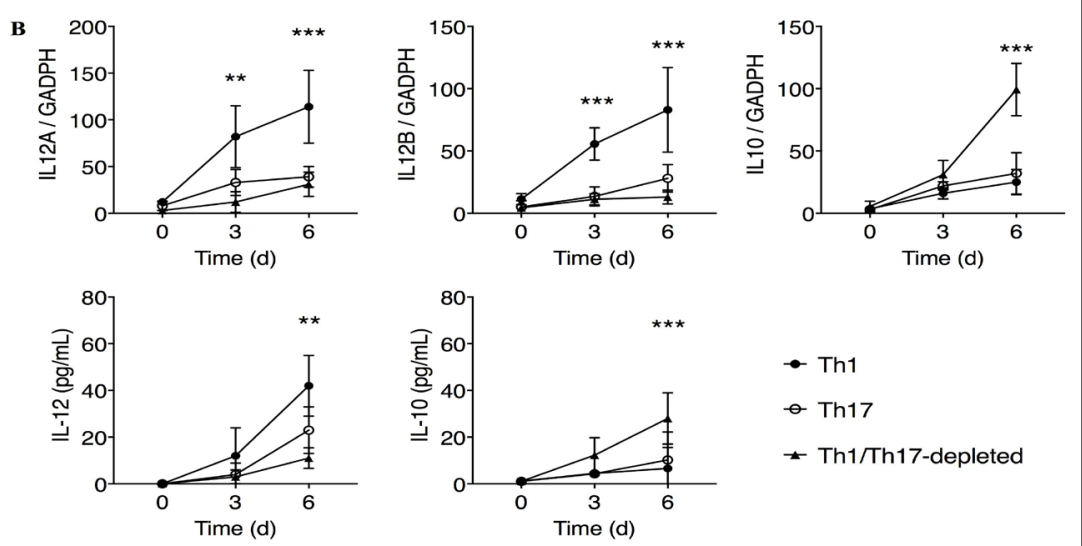

$\rightarrow$ Th1

- Th17

- Th1/Th17-depleted

and IL10 mRNA expression in macrophages, and the IL-12 and IL-10 concentration in culture supernatant in 12 AMD patients. Two-way ANOVA followed by Tukey's test. ${ }^{*} \mathrm{P}<0.05$. (B) The IL12A, IL12B, and IL10 mRNA expression in macrophages, and the IL-12 and IL-10 concentration in culture supernatant in 10 healthy controls. Two-way ANOVA followed by Tukey's test. ${ }^{*} \mathrm{P}<0.05$.

Th1 and Th17 cells from AMD patients induced higher MHC class I and/or class II expression in human RPE cell lines

To examine the effect of Th1 and Th17 cells on the inflammatory status of RPE cells, we utilized the human hTERT-immortalized RPE-1 cell line, and incubated RPE- 1 cells in a Transwell system with $\mathrm{CD} 4^{+} \mathrm{T}$ cells. In both AMD patients and healthy controls, we found that the expression of MHC class I molecules was universally present on RPE-1 cells and was significantly elevated in RPE-1 cells incubated with Th1 and Th17 cells (Fig. 5A and 5B). The expression of MHC class II molecules is usually observed in professional antigen-presenting cells, and can be conditionally induced in all cells. Very few RPE- 1 cells presented MHC class II expression, but coculture with Th1 cells resulted in significantly higher frequency of MHC class II-expressing RPE-1 cells (Fig. 5C and 5D). Together, these data suggested that Th1 and Th17 cells could upregulate MHC expression in RPE cells and promote interactions between RPE cells and T cells.

Th1 and Th17 partially mediated proinflammatory effects through IFN- $\gamma$ and IL-17 expression

Next, we investigated whether those Th1/Th17 cell-mediated effects were dependent on cytokine secretion. Previous coculture experiments were repeated with the addition of an IFN- $\gamma$ neutralizing antibody or corresponding isotype control in cocultures with Th1 


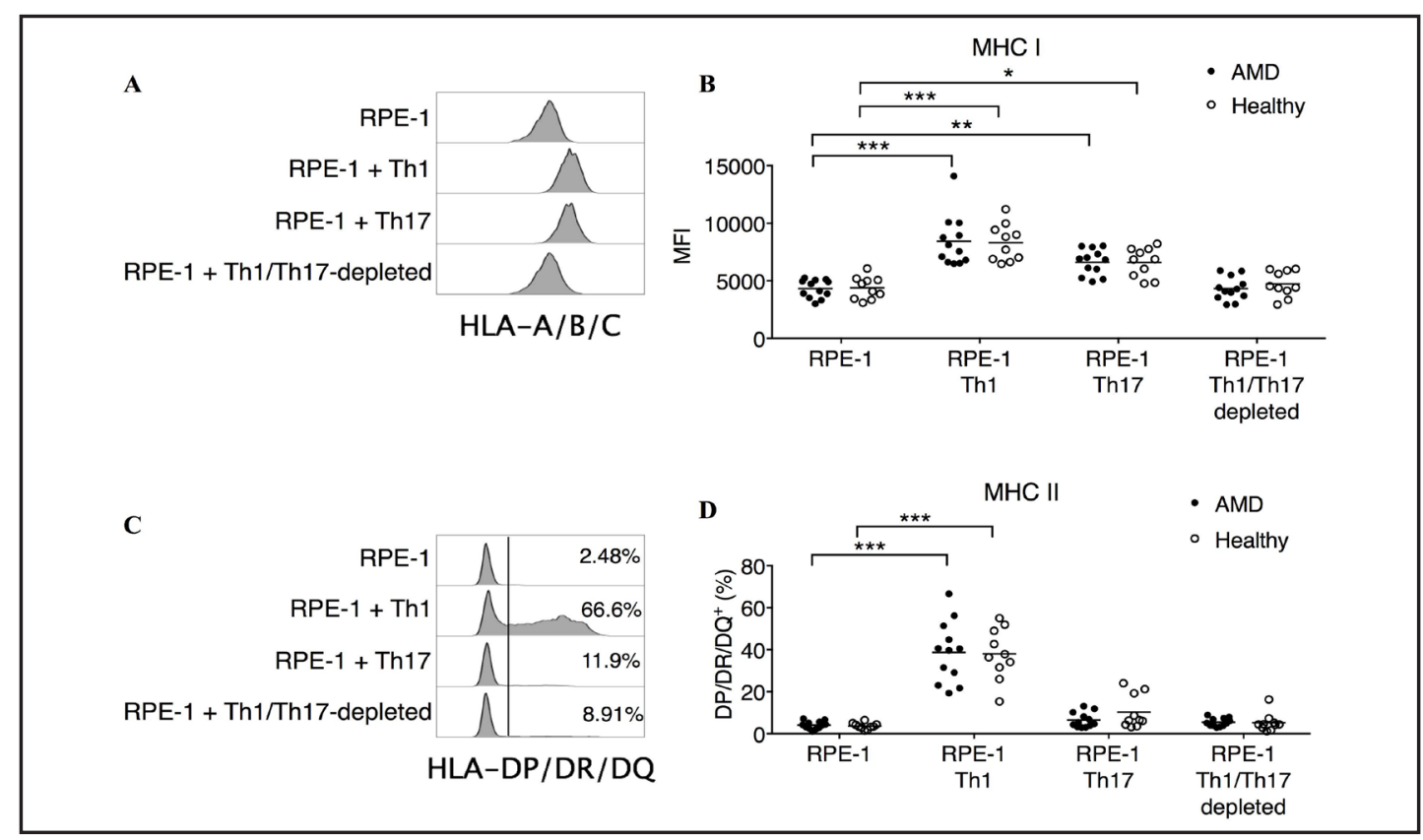

Fig. 5. Th1 and Th17 cells from AMD patients altered the expression of MHC molecules in human RPE-1 cell line. RPE-1 cells were incubated alone, or with anti-CD3/CD28-stimulated sorted CXCR3 ${ }^{+} \mathrm{CD} 4{ }^{+}(\mathrm{Th} 1)$, $\mathrm{CCR}^{+} \mathrm{CCR}^{+} \mathrm{CD}_{4}^{+}$(Th17) cells, or Th1/Th17-depleted CD4+ $\mathrm{T}$ cells for $72 \mathrm{~h}$ in a transwell system. The RPE1 cells were then harvested for flow cytometry staining. (A) Expression of MHC class I molecules by RPE-1 cells after coculturing with various $\mathrm{CD}^{+}{ }^{+} \mathrm{T}$ cell subsets from one representative AMD individual. (B) The MFI of MHC class I molecules by RPE-1 cells after after coculturing with various CD4+ $\mathrm{T}$ cell subsets from all AMD patients and healthy controls. Two-way ANOVA followed by Tukey's test. ${ }^{*} \mathrm{P}<0.05$. ${ }^{* *} \mathrm{P}<0.01$. ${ }^{* * *} \mathrm{P}<0.001$. (C) Expression of MHC class II molecules by RPE-1 cells after coculturing with various CD4+ ${ }^{+}$cell subsets from one representative AMD individual. (D) The percentage of MHC class II-expressing cells in RPE-1 cells after after coculturing with various $\mathrm{CD} 4^{+} \mathrm{T}$ cell subsets from all AMD patients and healthy controls. Two-way ANOVA followed by Tukey's test. *** $\mathrm{P}<0.001$.

cells and an IL-17 neutralizing antibody or corresponding isotype control in cocultures with Th17 cells. In AMD patients (Fig. 6A), we found that neutralizing IFN- $\gamma$ or IL-17 resulted in significantly less $I L 12 A$ expression but no significant change in IL12B. Neutralizing IFN- $\gamma$ or IL-17 also resulted in significantly lower level of MHC class I expression in RPE-1 cells. In addition, the percentage of MHC class II-expressing RPE-1 cells was significantly lower when IFN- $\gamma$ was neutralized. In healthy controls (Fig. 6B), neutralizing IFN- $\gamma$ or IL-17 resulted in significantly less $I L 12 A$ expression and significant change in $I L 12 B$. Neutralizing IFN $-\gamma$ significantly reduced the expression of MHC class I and MHC class II molecules, while neutralizing IL-17 did not significantly alter MHC expression. Together, we found that in both AMD patients and healthy controls, IFN- $\gamma$ and IL-17 secretion partially mediated the inflammatory effects of Th1 and Th17 cells, respectively.

\section{Discussion}

Accumulating evidence demonstrates that AMD represents yet another low-grade chronic inflammatory disease. Many studies in animal models have established causal links between retinal damage and proinflammatory pathways [20-22]. In humans, many studies have shown that AMD patients presented higher expression of proinflammatory cytokines and altered phenotype and functions of immune cells [16, 23, 24]. This study demonstrated that AMD patients also presented an imbalance in the composition of $\mathrm{CD} 4^{+} \mathrm{T}$ 
Fig. 6. Neutralizing IFN- $\gamma$ or IL-17 partially reduced the proinflammatory effects mediated by Th1 and Th17 cells. The Th1, Th17, monocyte/macrophage, and RPE-1 coculture experiments were repeated with the addition of IFN- $\gamma$ neutralizing antibody or corresponding isotype control to cocultures with Th1 cells, and IL-17 neutralizing antibody or corresponding isotype control to cocultures with Th17 cells. (A) The expression of IL12A and IL12B by macrophages following coculture with Th1 and Th17 cells from AMD patients and IFN- $\gamma$ or IL-17 neutralizing antibodies or isotype controls, and the expression of MHC class I and class II molecules by RPE-1 cells following coculture with Th1 and Th17 cells and IFN- $\gamma$ or IL-17 neutralizing antibodies or isotype controls. Wilcoxon test. $\quad * \mathrm{P}<0.05 . \quad{ }^{*} \mathrm{P}<0.01$. ${ }^{*} * * P<0.001$. (B) The expression of IL12A and IL12B by

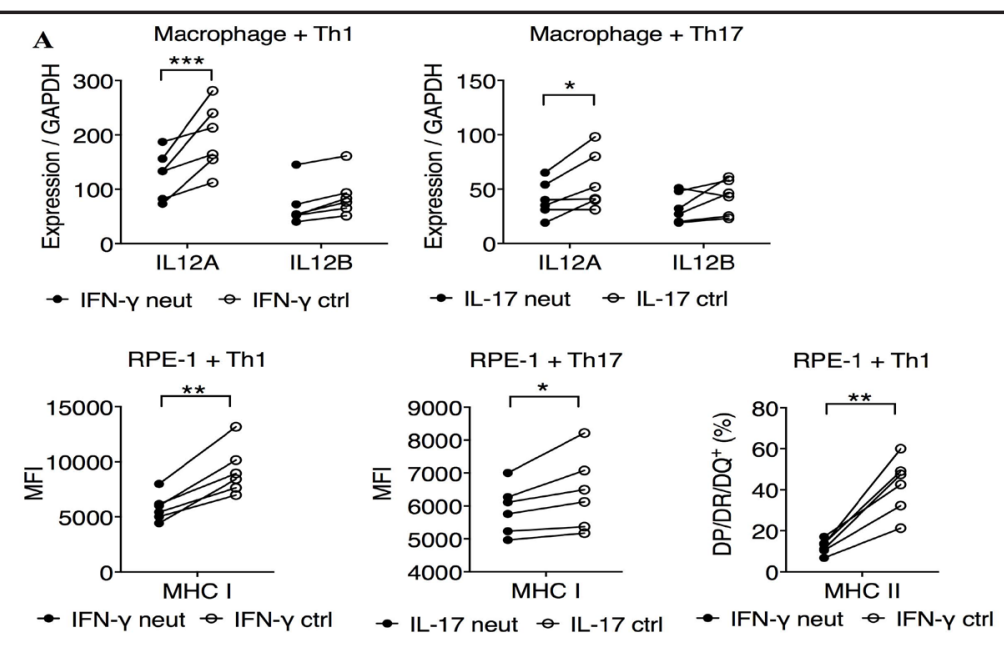
$\bullet$ IFN-Y neut $\bullet$ IFN-Y ctr

IL-17 neut IL-17 ctrl
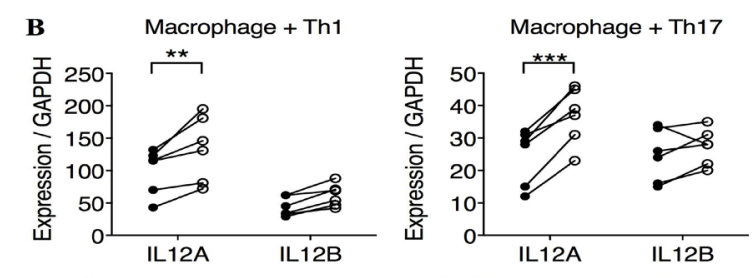

- IFN-Y neut $\bullet$ IFN-Y ctrl

- IL-17 neut $\odot$ IL-17 ctrl

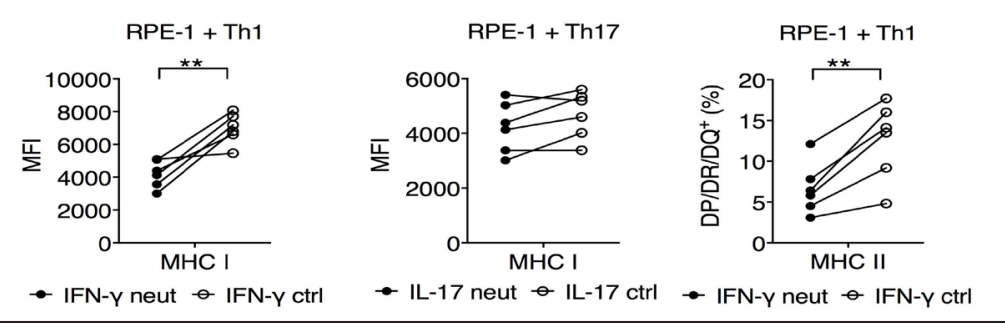

macrophages following co-

culture with Th1 and Th17 cells from healthy controls and IFN- $\gamma$ or IL-17 neutralizing antibodies or isotype controls, and the expression of MHC class I and class II molecules by RPE-1 cells following coculture with Th1 and Th17 cells and IFN- $\gamma$ or IL-17 neutralizing antibodies or isotype controls. Wilcoxon test. ${ }^{* *} \mathrm{P}<0.01$. $* * * \mathrm{P}<0.001$.

cells. This imbalance was shifted toward the Th1/Th17 cell subtype, which could have potent proinflammatory effects on both the macrophages, a powerful mediator of inflammation and tissue damage in the ocular region, and the RPE-1 cell line, a model of human RPE cells.

Another recent investigation by Singh et al. also examined the composition of $\mathrm{T}$ cells in the peripheral blood [25]. The authors defined Th1 cells as CD4 ${ }^{+} \mathrm{CXCR} 3^{+} \mathrm{IL} 12 \mathrm{RB} 2^{+}$cells and Th17 cells as CD $4^{+} \mathrm{CCR} 6^{+}{ }^{+} \mathrm{IL}_{2} 3 \mathrm{R}^{+}$cells, and observed that exudative AMD patients presented lower $\mathrm{CD} 4^{+} \mathrm{CXCR} 3^{+} \mathrm{IL} 12 \mathrm{RB} 2^{+}$cell frequency. A potential issue of this previous study was that the authors identified Th1 and Th17 cells by surface marker expression but not functional characteristics. Examinations by surface markers would be unable to identify whether these Th1 cells actually presented higher activation status. In our study, we defined Th1 and Th17 cells functionally by the expression of characteristic cytokines, and found that the frequencies of IFN- $\gamma$ - and IL-17-expressing CD4 ${ }^{+} \mathrm{T}$ cells, as well as the levels of IFN- $\gamma$ and IL-17 expression by CD4 ${ }^{+} \mathrm{T}$ cells, were significantly upregulated in AMD patients. Hence, the discrepancy in our conclusions likely arose from the different definitions being used to 
identify Th1 and Th17 cells. A more comprehensive gene expression analysis in circulating $\mathrm{CD} 4^{+} \mathrm{T}$ cells would be helpful to determine this issue.

The functional characteristics of Th1 and Th17 cells in AMD patients was not explored in previous investigations but was examined in our study. Using CXCR ${ }^{+}$and $\mathrm{CCR} 4^{+}{ }^{+} \mathrm{CRR} 6^{+}$as surface markers for Th1 and Th17 cells, respectively, we found that Th1 and Th17 cells from AMD individuals could potently promote the differentiation of M1, but not M2 macrophages. Given that M1 macrophages were previously linked with the development of retinal lesions in mouse model [20], Th1 cell and Th17 cells might function to accelerate the development of AMD and exacerbate the symptoms. Further research in animal models is necessary to establish a causal link. We also observed that Th1 and Th17 cells both enhanced the expression of MHC class I molecules in RPE-1 cells, while Th1 also increased the frequency of MHC class II-expressing cells in RPE-1 cells, thus potentiating these cells to mediate antigen-specific interaction with $\mathrm{T}$ cells. The clinical implications of this finding require further studies. These results also raised the question of whether Th1 and Th17 responses could act as a treatment target, such that by suppressing Th1 and Th17 inflammation, the development of AMD could be slowed or averted. Of note, Th1 and Th17 cells isolated from healthy individuals presented a similar function in promoting the differentiation of M1 macrophages and enhancing the MHC class I and class II molecule expression by RPE-1 cells, suggesting that the extent of Th1 and Th17 inflammation, but not the categorical function of Th1 and Th17 cells, was altered in AMD.

By blocking secreted IFN- $\gamma$ and IL-17, the IL12A expression and MHC class I and class II molecule expression could be significantly reduced, demonstrating that the proinflammatory effects of Th1 and Th17 cells were at least in part mediated by cytokines. However, besides proinflammatory cytokines, $\mathrm{T}$ cells also interact with macrophages through multiple surface molecules. The specific ones that could influence macrophage differentiation are yet unclear. Current paradigm support the opposite mechanism, that the different subsets of macrophages promote the differentiation of $T$ cell subsets [26]. Th1 and Th17 could also secrete a multitude of other cytokines, such as TNF, which could contribute to the development of M1 macrophages. The specific role of other cytokines in AMD should be examined in future studies.

Together, our results established a correlational, but not causal, link between Th1/Th17 inflammation and AMD development. A major limitation of this study is that we performed the experiments using fractionated $\mathrm{CD} 4^{+} \mathrm{T}$ cell subsets in isolated in vitro systems, which could not take the interactions between $\mathrm{T}$ cell subsets into account. In uveitis, another ocular inflammatory disease with Th1 and Th17 involvement $[27,28]$, blocking the Th1 response could result in the enhancement of Th17 response, and vice versa. Hence, more animal experiments are required to examine whether suppressing Th1 and Th17 response could act as an effective treatment strategy. Another important unanswered question is why the AMD patients were enriched with Th1 and Th17 cells. It was suggested that oxidative insults tended to accumulate with advancing age, which could gradually lead to exacerbated inflammation in the absence of pathogenic infections. The induction mechanism of Th1 and Th17 in AMD patients still requires further analyses.

\section{Disclosure Statement}

None.

\section{References}

1 Wong T, Chakravarthy U, Klein R, Mitchell P, Zlateva G, Buggage R, Fahrbach K, Probst C, Sledge I, Sledge I: The Natural History and Prognosis of Neovascular Age-Related Macular Degeneration. Ophthalmology 2008;115:116-126. 


\section{Cellular Physiology Cell Physiol Biochem 2017;44:357-367 and Biochemistry \begin{tabular}{l|l} 
DOI: 10.1159/000484907 & $\begin{array}{l}\text { O 2017 The Author(s). Published by S. Karger AG, Basel } \\
\text { www.karger.com/cpb }\end{array}$
\end{tabular} \\ Chen et al.: Th1/Th17 Imbalance in AMD}

-2 Wong WL, Su X, Li X, Cheung CMG, Klein R, Cheng C-Y, Wong TY: Global prevalence of age-related macular degeneration and disease burden projection for 2020 and 2040: a systematic review and meta-analysis. Lancet Glob Heal 2014;2:e106-e116.

3 Wong TY, Liew G, Mitchell P: Clinical update: new treatments for age-related macular degeneration. Lancet 2007;370:204-206.

4 CATT Research Group, Martin DF, Maguire MG, Ying G, Grunwald JE, Fine SL, Jaffe GJ: Ranibizumab and Bevacizumab for Neovascular Age-Related Macular Degeneration. N Engl J Med 2011;364:1897-1908.

5 Ding X, Patel M, Chan C-C: Molecular pathology of age-related macular degeneration. Prog Retin Eye Res 2009;28:1-18.

6 Anderson DH, Mullins RF, Hageman GS, Johnson LV: A role for local inflammation in the formation of drusen in the aging eye. Am J Ophthalmol 2002;134:411-431.

7 Penfold PL, Liew SC, Madigan MC, Provis JM: Modulation of major histocompatibility complex class II expression in retinas with age-related macular degeneration. Invest Ophthalmol Vis Sci 1997;38:21252133.

8 Ambati J, Atkinson JP, Gelfand BD: Immunology of age-related macular degeneration. Nat Rev Immunol 2013;13:438-451.

9 Tuo J, Grob S, Zhang K, Chan C-C: Genetics of Immunological and Inflammatory Components in Age-related Macular Degeneration. Ocul Immunol Inflamm 2012;20:27-36.

10 Li C, Yuan J, Zhu YF, Yang XJ, Wang Q, Xu J, He ST, Zhang JA: Imbalance of Th17/Treg in Different Subtypes of Autoimmune Thyroid Diseases. Cell Physiol Biochem 2016;40:245-52.

11 Sokolove J, Lepus CM: Role of inflammation in the pathogenesis of osteoarthritis: latest findings and interpretations. Ther Adv Musculoskelet Dis 2013;5:77-94.

$\$ 12$ Lahoute C, Herbin 0, Mallat Z, Tedgui A: Adaptive immunity in atherosclerosis: mechanisms and future therapeutic targets. Nat Rev Cardiol 2011;8:348-358.

13 Liu Y, Su L, Lin Q, Han Y, You P, Fan Q: Induction of C-Mip by IL-17 Plays an Important Role in AdriamycinInduced Podocyte Damage. Cell Physiol Biochem 2015;36:1274-90.

14 Rocha VZ, Folco EJ, Sukhova G, Shimizu K, Gotsman I, Vernon AH, Libby P: Interferon-gamma, a Th1 cytokine, regulates fat inflammation: a role for adaptive immunity in obesity. Circ Res 2008;103:467-476.

15 Wang L, Wu G, Qin X, Ma Q Zhou Y, Liu S, Tan Y: Expression of Nodal on Bronchial Epithelial Cells Influenced by Lung Microbes Through DNA Methylation Modulates the Differentiation of T-Helper Cells. Cell Physiol Biochem 2015;37:2012-2022.

-16 Nassar K, Grisanti SSS, Elfar E, Lüke J, Lüke M, Grisanti SSS: Serum cytokines as biomarkers for age-related macular degeneration. Graefe's Arch Clin Exp Ophthalmol 2014;253:1-6.

-17 Liu Y, Zhao X, Zhong Y, Meng K, Yu K, Shi H, Wu B, Tony H, Zhu J, Zhu R, Peng Y, Mao Y, Cheng P, Mao X, Zeng Q: Heme oxygenase- 1 restores impaired GARPCD $4^{+} \mathrm{CD} 25^{+}$regulatory $\mathrm{T}$ cells from patients with acute coronary syndrome by upregulating LAP and GARP expression on activated T lymphocytes. Cell Physiol Biochem 2015;35:553-570.

-18 Hirota K, Yoshitomi H, Hashimoto M, Maeda S, Teradaira S, Sugimoto N, Yamaguchi T, Nomura T, Ito H, Nakamura T, Sakaguchi N, Sakaguchi S: Preferential recruitment of CCR6-expressing Th17 cells to inflamed joints via CCL20 in rheumatoid arthritis and its animal model. J Exp Med 2007;204:2803-2512.

19 Grunin M, Hagbi-Levi S, Chowers I: The role of monocytes and macrophages in age-related macular degeneration. Adv Exp Med Biol 2014;801:199-205.

-20 Cruz-Guilloty F, Saeed AM, Echegaray JJ, Duffort S, Ballmick A, Tan Y, Betancourt M, Viteri E, Ramkhellawan GC, Ewald E, Feuer W, Huang D, Wen R, Hong L, Wang H, Laird JM, Sene A, Apte RS, Salomon RG, Hollyfield JG, Perez VL: Infiltration of proinflammatory $\mathrm{m} 1$ macrophages into the outer retina precedes damage in a mouse model of age-related macular degeneration. Int J Inflam 2013;2013:503725.

-21 Luo C, Zhao J, Madden A, Chen M, Xu H: Complement expression in retinal pigment epithelial cells is modulated by activated macrophages. Exp Eye Res 2013;112:93-101.

22 Cruz-Guilloty F, Saeed AM, Duffort S, Cano M, Ebrahimi KB, Ballmick A, Tan Y, Wang H, Laird JM, Salomon RG, Handa JT, Perez VL: T cells and macrophages responding to oxidative damage cooperate in pathogenesis of a mouse model of age-related macular degeneration. PLoS One 2014;9:e88201.

-23 Falk MK, Singh A, Faber C, Nissen MH, Hviid T, Sørensen TL: Dysregulation of CXCR3 Expression on Peripheral Blood Leukocytes in Patients With Neovascular Age-Related Macular Degeneration. Investig Opthalmology Vis Sci 2014;55:4050. 
24 Grunin M, Burstyn-Cohen T, Hagbi-Levi S, Peled A, Chowers I: Chemokine Receptor Expression in Peripheral Blood Monocytes from Patients with Neovascular Age-Related Macular Degeneration. Investig Opthalmology Vis Sci 2012;53:5292.

25 Singh A, Subhi Y, Krogh Nielsen M, Falk MK, Matzen SMH, Sellebjerg F, Sørensen TL: Systemic frequencies of T helper 1 and T helper 17 cells in patients with age-related macular degeneration: A case-control study. Sci Rep 2017;7:605.

-26 Italiani P, Boraschi D: From Monocytes to M1/M2 Macrophages: Phenotypical vs. Functional Differentiation. Front Immunol 2014;5:514.

27 Amadi-Obi A, Yu C-R, Liu X, Mahdi RM, Clarke GL, Nussenblatt RB, Gery I, Lee YS, Egwuagu CE: TH17 cells contribute to uveitis and scleritis and are expanded by IL-2 and inhibited by IL-27/STAT1 Nat Med 2007;13:711-718.

28 Foxman EF, Zhang M, Hurst SD, Muchamuel T, Shen D, Wawrousek EF, Chan C-C, Gery I: Inflammatory mediators in uveitis: differential induction of cytokines and chemokines in Th1-versus Th2-mediated ocular inflammation. J Immunol 2002;168:2483-2492. 